\title{
Problems evaluation for TRIZ method using AHP: case study on car's dashboard improvement design concepts
}

\begin{abstract}
This study established a support tool framework for TRIZ practitioners to specify the problems statement stage in TRIZ method through utilizing the Multi Criteria Decision Method (MDCM) of Analytical Hierarchy Process (AHP). The proposed framework was analyzed and evaluated by a case study of carôs dashboard. From a list of problems and customer complaints gathered by survey, the problems were evaluated through AHP method and resulted only three major problems that should be highlighted for further steps. Results indicated that the improvement design generated by both methods could came out an appropriate new design effectively and avoided the cost waste during the product design and development processes.
\end{abstract}

Keyword: Analytical hierarchy process; Product design; TRIZ 